\title{
Elaboration of C/C Composites Based on the Infiltration of a Hydrocarbon Precursor in Supercritical State into the Preform
}

\author{
L. Maillé*, A. Guette, R. Pailler, Y. Le Petitcorps, P. Weisbecker \\ Univ. de Bordeaux, LCTS, UMR 5801, F-33600, Pessac \\ *maille@lcts.u-bordeauxl.fr
}

Keywords: supercritical fluid, Chemical Vapor Infiltration, C/C composites

\begin{abstract}
A work based on the development of a new process for the fabrication of a $\mathrm{C} / \mathrm{C}$ composite for aeronautic and aerospace industries, in order to reduce the infiltration duration of the carbon preform, is reported in this paper. The infiltration of a carbon fibrous preform by the mean of a hydrocarbon in the supercritical fluid state is done at high temperature in order to get a carbon matrix. The microstructure of the pyrocarbon coating is characterized by SEM and TEM. The experimental parameters (temperature, hydrocarbon pressure, residence time) are tuned in order to elaborate the carbon matrix. The best conditions lead to a rapid densification in-depth from the top of the preform. After several experiments, the densification has been improved.
\end{abstract}

\section{Introduction}

Ceramic Matrix Composites are developed for aeronautic and spatial applications [1-2] for their refractoriness and their low density. These composites are usually get by a long infiltrating step of a weaved preform by Chemical Vapor Infiltration (CVI) using a hydrocarbon precursor as the propane for example [1]. However, the CVI-step is a rather long process which is a huge drawback. As a result, the manufacturing cost of these composites is very expensive. In order to reduce the cost, other processes can also be employed to get the matrix, as liquid phase routes with mineral charges [3-9].

In this paper, we explore an original and new densification process in order to elaborate a Carbon/Carbon (C/C) composite: the Chemical Supercritical Fluid Infiltration. A supercritical fluid is a substance at a temperature and pressure above its thermodynamic critical point. Its properties are simultaneously those of gases and liquids [10]. Indeed, it has the unique ability to diffuse through porous solids like a gas, and to dissolve materials like a solvent. This 
combination of the solvent ability and the high diffusivity should enable a rapid infiltration and a good densification of the porous preform.

\section{Materials and experimental procedures}

Two types of materials are used: (i) graphite pipes (length $6 \mathrm{~cm}$, diameter $0.6 \mathrm{~cm}$ ) are used as a substrate for kinetic studies of the deposition rate, and (ii) 3D porous carbon fibrous preforms (length $2 \mathrm{~cm}$, diameter $1.5 \mathrm{~cm}$ ) for infiltration study. The initial open porosity of the preforms is around $77 \%$.

A cold wall reactor schematic represented in Fig. 1, is used at high pressure, in batch flow. It is made of inconel alloys. The graphite pipe is heated, using the Joule effect. The temperature is measured by a thermocouple located inside the graphite pipe protected by an alumina tube. The carbon films or matrix are elaborated using the methane as the hydrocarbon precursor. The kinetic of the carbon deposit can be studied by modifying the values of the residence time of the methane. The other parameters (initial pressure, initial temperature) are kept constant. The temperature selected for each samples is $950^{\circ} \mathrm{C}$, with an initial pressure of 50 bars, in these conditions the methane is a supercritical fluid $\left(\mathrm{T}_{\text {critical }}=-82.6^{\circ} \mathrm{C}\right.$ and $\left.\mathrm{P}_{\text {critical }}=46 \mathrm{bar}\right)$. For kinetic studies of the deposition rate, thin films are performed on the graphite pipes from 2.5 to 20 minutes of deposition. The duration selected (cf. Table 1) for one step infiltration of the carbon matrix texture $3 \mathrm{D}$, is fixed to 60 minutes.

Another experiment with several steps of infiltration, described table 1, is used to improve the matrix densification, with an initial pressure of 50 bar. The polished cross sections of thin carbon films or matrix are observed with an optical microscope, (Reichert-Jung MEF3).

\section{Results and discussion}

\subsection{Pyrocarbon coating on a graphite pipe}

With the variation of the residence times, it is possible to reach an important thickness of pyrocarbon: from $3 \mu \mathrm{m}$ to $30 \mu \mathrm{m}$ for $2.5-5$ minutes and 10-20 minutes respectively. It confirms the interest to work using a supercritical fluid, by comparison, several hours are necessary to reach the same thickness with the CVI-process [11].

The thickness of the pyrocarbon coating varies significantly along the pipe due to a presence of a temperature gradient (Fig. 2). The temperature is a particularly significant and sensitive parameter. 
The texture of the pyrocarbon coating is similar to the one elaborated with CVI-process (Fig. 3). Pyrocarbon thin film is characterized by a cone-like growth structure [12].

In order to demonstrate the feasibility to perform a pyrocarbon thin film with a hydrocarbon precursor in supercritical state, carbon preforms have been densified with the same protocol.

\subsection{Infiltration of the pyrocarbon matrix into a fibrous preform}

The influence of the hydrocarbon precursor residence time during the matrix infiltration is studied. The temperature and the initial pressures are fixed at $950^{\circ} \mathrm{C}$ and 50 bars respectively. These first experiments show a good densification (infiltrated of 0.5 minute depth of the preform) for a short residence time (10 minutes). However, as it could be observed on the sample performed with residence time of $60 \mathrm{~min}$, the densification is not complete (Fig. 4). Various pores are present between some fibers even on the surface of the preform.

The cross sections observations show a densification thickness of $1.5 \mathrm{~mm}$ in the depth of the preform with a residence time of 60 minutes (against $0.5 \mathrm{~mm}$ with 10 minutes). Consequently, with this experiment, the densification is significantly improved to the first one, but a lot of porosities are presents in the matrix. However, the pyrocarbon thin film is homogeneous in thickness and adherent to the fiber.

In order to improve the densification, other experiments are performed, using the semi continuous feeding reactor (table 1). Five steps of infiltration have been done, equivalent to $42 \mathrm{~min}$ for the residence time. The change in the temperature between the step 3 and 4 was done in order to introduce the pyrocarbon at low temperature inside the preform, and to finish the densification at high temperature, to fill the porosities.

The matrix densification using the semi continuous feeding of the reactor has been improved. After these five steps, the gain mass of the sample is increased to $90 \%$ by this way. Whereas it varies from $41 \%$ and $43 \%$ for one batch of 10 minutes and 60 minutes respectively (table 1). It is possible to compare the cross sections of the figure 3 and 4 , and to observe an improvement of the infiltration with the semi continuous feeding reactor. A good densification thickness of $1.5 \mathrm{~mm}$ in the depth of the preform is observed. A pyrocarbon coating is observed around each fiber until $2.5 \mathrm{~mm}$ in-depth of the preform (figure $5 \mathrm{a}-\mathrm{b}$ ). TEM characterizations confirm the presence of pyrocarbon, and an anisotropy structure (Fig. $6)$. 


\section{Conclusion}

The objective of this study was to demonstrate that a pyrocarbon coating could be deposited around each carbon fibres within a 3D carbon preform with a methane precursor in its supercritical state. A device has been set up for this purpose alloying to work under a pressure of $50-100$ bar at $950-1050^{\circ} \mathrm{C}$ for less than one hour of infiltration. According to the experimental parameters chosen the infiltration depth of the preform could reach $1.5 \mathrm{~mm}$ and a pyrocarbon coating is observed around each fiber until $2.5 \mathrm{~mm}$ in-depth. The results were interesting, however other experiments have to be conducted in order to get a full infiltrated preforms if necessary.

\section{Acknowledgment}

The authors would like to thank S. Couthures for the fabrication of the experimental process and assistance in testing.

\section{References}

1. Naslain R. SiC-Matrix Composites: Non brittle Ceramics for Thermo-Structural Application. International Journal of Applied Ceramic Technology 2005; 2: 75-84.

2. Naslain R., Introduction aux matériaux composites. Tome 2 : Matrices métalliques et céramiques, Edition du CNRS, France 1979.

3. Rietveld H.M. A profile refinement method for nuclear and magnetic structures. Journal of Applied Crystallography 1969; 2: 65-\&.

4. Rodriguez-Carvajal J. Recent advances in magnetic structure determination by neutron powder diffraction. Physica B: Condensed Matter 1993; 192: 55-69.

5. Sambasivan S., Petuskey W.T. Phase chemistry in the system - thermochemical review with phase - stability diagrams. Journal of Materials Research 1994; 9: 23622369.

6. Paulasto M., Kivilahti J.K., Van Loo F.J.J. Interfacial reactions in Ti/Si ${ }_{3} \mathrm{~N}_{4}$ and TiN/Si diffusion couples. Journal of Applied Physics 1195; 77: 4412 - 4416.

7. Hillig W.B. Making ceramic composites by melt infiltration. American Ceramic Society Bulletin 1994; 73: 56-62.

8. Le Ber S., Dourges M.A., Maillé L., Pailler R., Guette A. Ceramic matrix composites densification by active filler impregnation followed by PIP process. Ceramic Transactions 2010; 215: 113-123. 
9. Magnant J., Maillé L., Pailler R., Ichard J.C., Guette A., Rebillat F., Philippe E., Carbon fiber/reaction-bonded carbide matrix for composite materials - Manufacture and characterization, Journal of the European Ceramic Society 2012; 32:4497-4505.

10. Le Trequesser Q., Mesguich D., You E., Aymonier C., Watkins J. Supercritical fluid deposition of compositionally uniform yttria stabilized zirconia films. The Journal of Supercritical Fluids 2012; 66: 328-332.

11. Christin F., Design - fabrication and application of thermostructural composites (TSC) like $\mathrm{C} / \mathrm{C}-\mathrm{C} / \mathrm{SiC}$ and $\mathrm{SiC} / \mathrm{SiC}$ composites. Advanced engineering materials 2002; 4: 903-912.

12. Bourrat X., Fillion A., Naslain R., Chollon G., Brendlé M. Regenerative laminar pyrocarbon. Carbon $2002 ; 40: 2931-2945$. 


\section{LIST OF FIGURE AND TABLE CAPTIONS}

\section{$\underline{\text { FIGURES }}$}

Figure 1. Schematic representation of the cold wall reactor.

Figure 2. Influence of the gradient temperature of the graphite pipe on the pyrocarbon thickness.

Figure 3. Cross section of a pyrocarbon layer deposited on the carbon pipe (pyrocarbon elaborated with 20 minutes of residential time).

Figure 4. Cross sections of the infiltrated of $\mathrm{C} / \mathrm{C}$ composite with a residence time of $60 \mathrm{~min}$, at different scale.

Figure 5. Cross section of sample realised with the five steps described in table 1.

Figure 6. TEM characterizations.

\section{$\underline{\text { TABLE }}$}

Table 1. Infiltration conditions of the $3 \mathrm{D}$ carbon preforms. 
TABLE 1

\begin{tabular}{|c|c|c|c|c|}
\hline samples & temperatures $\left({ }^{\circ} \mathbf{C}\right)$ & durations (min) & conditions & Mass gain \\
\hline A & 950 & 60 & One step infiltration & $43 \%$ \\
\hline \multirow{4}{*}{ B } & & & Semi-continuous \\
& & & feeding & $41 \%$ \\
\cline { 2 - 4 } & 950 & 10 & Step 1(*) & \\
\cline { 2 - 5 } & 950 & 10 & Step 2 & Step 3 \\
& 950 & 10 & Step 4 & $90 \%$ \\
\hline
\end{tabular}

(*) For each step, the vessel is evacuated and then feed with the $\mathrm{CH}_{4}$ precursor at a constant pressure of 50 bar. 


\section{FIGURE 1}

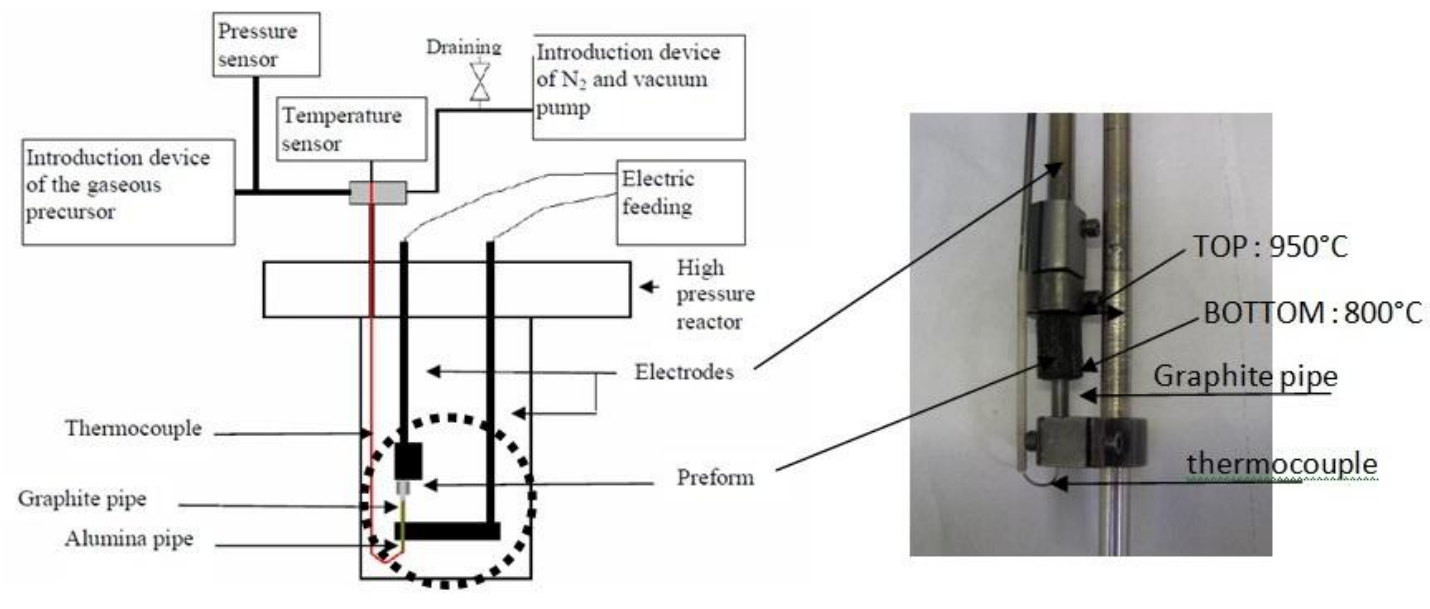


FIGURE 2

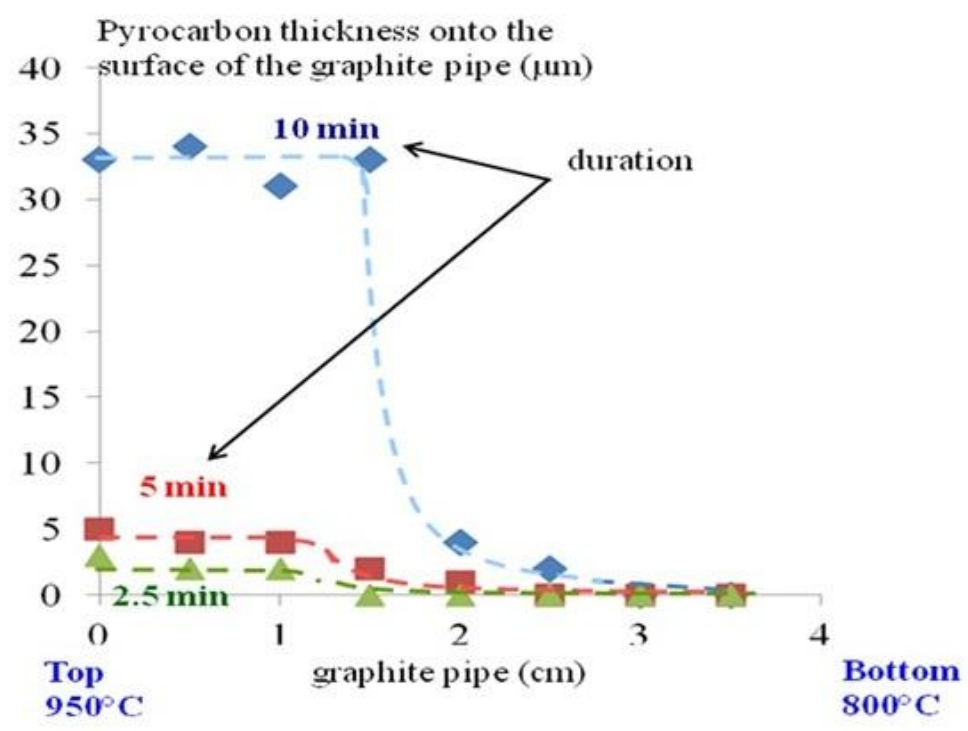


FIGURE 3

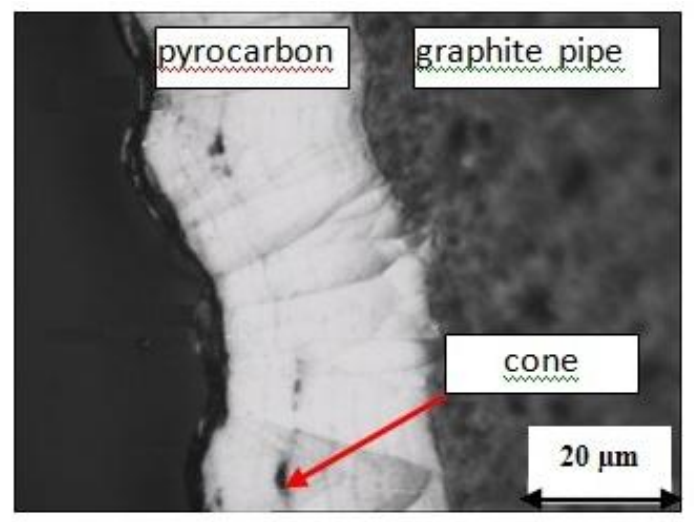


FIGURE 4
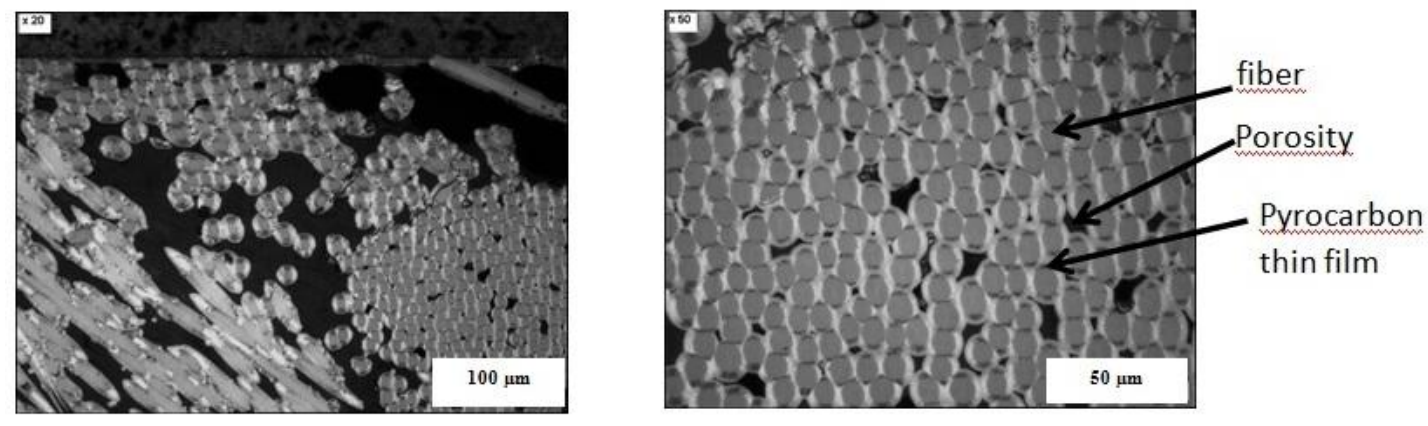
FIGURE 5
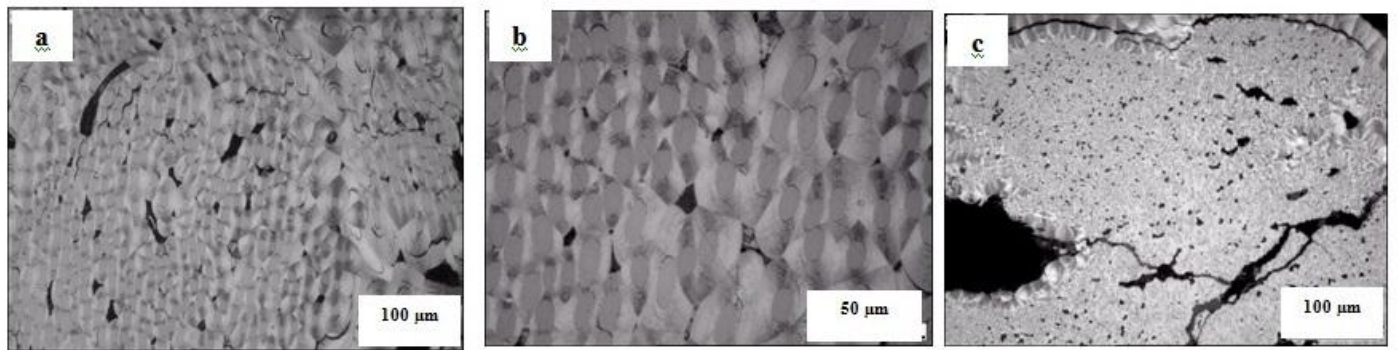


\section{FIGURE 6}

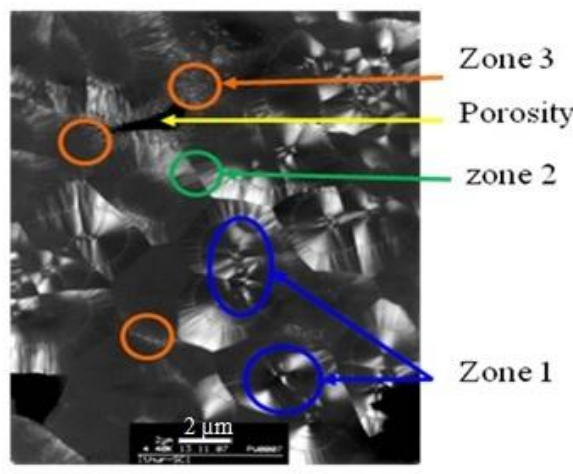

TEM $(x+400)$
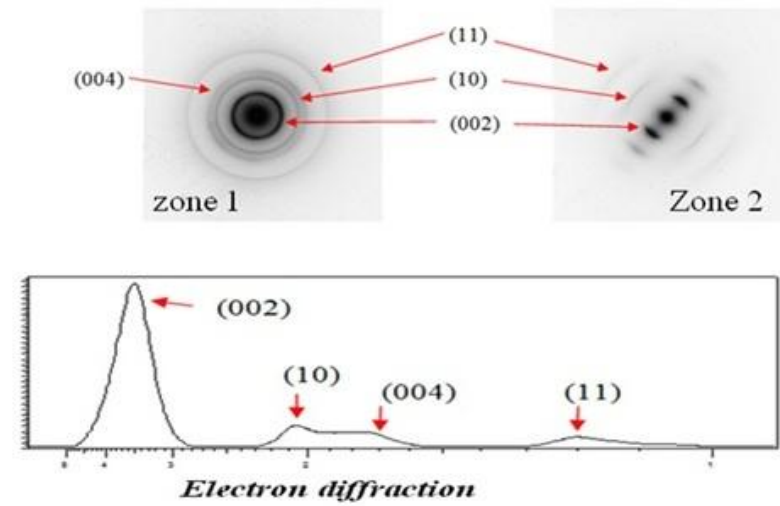